\title{
The effects of variation in snow properties on passive microwave snow mass estimation
}

Article

Accepted Version

Davenport, I., Sandells, M. and Gurney, R. (2012) The effects of variation in snow properties on passive microwave snow mass estimation. Remote Sensing of the Environment, 118 (1). pp. 161-175. ISSN 0034-4257 doi:

https://doi.org/10.1016/j.rse.2011.11.014 Available at https://centaur.reading.ac.uk/25685/

It is advisable to refer to the publisher's version if you intend to cite from the work. See Guidance on citing.

To link to this article DOI: http://dx.doi.org/10.1016/j.rse.2011.11.014

Publisher: Elsevier

All outputs in CentAUR are protected by Intellectual Property Rights law, including copyright law. Copyright and IPR is retained by the creators or other copyright holders. Terms and conditions for use of this material are defined in the End User Agreement.

www.reading.ac.uk/centaur 
Central Archive at the University of Reading

Reading's research outputs online 
1 Title: The effects of variation in snow properties on passive microwave snow mass estimation

$3 \quad$ I.J. Davenport ${ }^{1}$, M.J. Sandells ${ }^{1}$, R.J. Gurney ${ }^{1}$

${ }^{1}$ University of Reading, Harry Pitt Building, 3 Earley Gate, University of Reading, Reading, RG6 $6 \quad 6 \mathrm{AL}, \mathrm{UK}$

\section{Abstract}

Estimating snow mass at continental scales is difficult, but important for understanding land-

11 atmosphere interactions, biogeochemical cycles and the hydrology of the Northern latitudes.

12 Remote sensing provides the only consistent global observations, but with unknown errors. We test

13 the theoretical performance of the Chang algorithm for estimating snow mass from passive microwave measurements using the Helsinki University of Technology (HUT) snow microwave emission model. The algorithm's dependence upon assumptions of fixed and uniform snow density and grainsize is determined, and measurements of these properties made at the Cold Land Processes

17 Experiment (CLPX) Colorado field site in 2002-2003 used to quantify the retrieval errors caused by

18 differences between the algorithm assumptions and measurements. Deviation from the Chang

19 algorithm snow density and grainsize assumptions gives rise to an error of a factor of between two and three in calculating snow mass. The possibility that the algorithm performs more accurately

21 over large areas than at points is tested by simulating emission from a $25 \mathrm{~km}$ diameter area of snow

22 with a distribution of properties derived from the snow pit measurements, using the Chang

23 algorithm to calculate mean snow-mass from the simulated emission. The snow mass estimation

24 from a site exhibiting the heterogeneity of the CLPX Colorado site proves only marginally different than that from a similarly-simulated homogeneous site. The estimation accuracy predictions are 
tested using the CLPX field measurements of snow mass, and simultaneous SSM/I and AMSR-E snow pit measurements.

Keywords: snow, remote sensing, passive microwave

\section{Introduction}

Remote sensing is the only feasible way to monitor the global distribution of snow mass, which is important for water resource management, environmental risk assessment and to determine the sensitivity of climate to change (Randall et al., 2007). Comparisons between global models, reanalysis data and satellite observations have revealed differences in distribution and magnitude of snow water equivalent (Clifford, 2010), but errors in the observations must be quantified in order to assess the accuracy of the models. Chang et al. (1987) used a simple model of soil/snow microwave emission to devise a means for estimating snow water equivalent (SWE) in mm from passive microwave measurements, by multiplying the difference between the horizontally-polarised $19 \mathrm{GHz}$ and $37 \mathrm{GHz}$ emission by a factor of 4.77 , assuming snow density of $300 \mathrm{kgm}^{-3}$. This technique, which we refer to here as the Chang algorithm, was recommended for snow no deeper than a metre, approximately equivalent to a snow water equivalent of $300 \mathrm{~mm}$, due to increasing non-linearity in the relationship around this depth. The Chang algorithm has, with minor variations, been operationally used since 1987 to estimate snow mass globally from satellite observations from instruments such as SSM/I and AMSR-E.

There have been a few comparisons between snow mass measured by the Chang algorithm and by ground-based observation, showing both substantial over- and underestimation. Armstrong \& Brodzik (2000) found a substantial underestimation around 20-40\% in SWE when applying the Chang algorithm to snow in the former Soviet Union in the Winter 1988-89 season, for SWE 
between $10 \mathrm{~mm}$ and $100 \mathrm{~mm}$. Pardé et al. (2007) found the Chang algorithm to overestimate snow mass with an RMSE of 40mm over Winter in 2002-2003 in Central Canada, for a range of SWE between about $20 \mathrm{~mm}$ and $150 \mathrm{~mm}$. They improved this to an RMSE of $12 \mathrm{~mm}$ by incorporating a simultaneous retrieval of snow grain size into an inversion of the Helsinki University of Technology (HUT) model (Pulliainen et al., 1999). Butt (2009) demonstrated that a retrieval applying the Chang algorithm to SSM/I observations of snow in the UK with a mean depth of 90mm (so a SWE approximately $30 \mathrm{~mm}$ ), with depths up to $500 \mathrm{~mm}$, underestimated snow depth by a mean of $51 \%$. He also demonstrated an approach to resolving this by a simultaneous retrieval of snow grain size, improving performance to a mean $11 \%$ overestimate. This seems to indicate a considerable range of performance of the Chang algorithm, apparently dependent upon the physical characteristics of the snow local to each study. We aim here to explore more generally the relationship between the physical characteristics of snow and the efficacy of the Chang algorithm, illustrate how simulating the retrieval can identify the flawed assumptions, and validate the approach by estimating snow mass from remotely-sensed data in an area with an extensive set of physical measurements.

By modelling the emission of microwave radiation by a snowpack and the underlying ground, we firstly test the dependence of the microwave emission of a snowpack/ground combination upon the physical characteristics of the snow, using the Helsinki University of Technology (HUT) snow microwave emission model, and use this to estimate how the Chang algorithm performance would be affected by variation in snow properties. To evaluate the effects of this variation on snow mass estimation, we also need to know how much variability in these properties is typically found in snow. We study this by using the planimetrically extensive measurements made at snow pits in the CLPX Colorado site in 2002-3. We examine how accurately the Chang algorithm would retrieve snow mass from snow with these characteristics by simulating emission with the HUT emission model driven by measured snow properties. Finally, we compare our predictions of the accuracy of 
8

the Chang algorithm over the CLPX area to the application of the algorithm to SSM/I and AMSR-E measurements.

\section{Methods}

\subsection{The sensitivity of the Chang algorithm to snow grain diameter and density}

Most SWE retrievals make use of an empirical retrieval first derived by Chang et al. (1987), consisting of a linear fit to brightness temperatures at $18 \mathrm{GHz}$ and $37 \mathrm{GHz}$, equation (1):

$$
\mathrm{SWE}(\mathrm{mm})=4.77\left(\mathrm{~TB}_{18 \mathrm{H}}-\mathrm{TB}_{37 \mathrm{H}}\right) \quad \text { Equation (1) }
$$

where $\mathrm{TB}_{18 \mathrm{H}}$ refers to the microwave brightness temperature measured at $18 \mathrm{GHz}$ at horizontal polarization, and $\mathrm{TB}_{37 \mathrm{H}}$ refers to the microwave brightness temperature measured at $37 \mathrm{GHz}$ at horizontal polarization. The gradient of the linear fit, in this equation 4.77 , depends on the density and grain diameter of the snowpack. Whilst it is clear that a density of $300 \mathrm{~kg} \mathrm{~m}^{-3}$ was used to determine the gradient, the grain diameter used is uncertain. Chang et al. (1987) refer to a figure which shows brightness temperature curves as a function of SWE for two different grain radii, $0.3 \mathrm{~mm}$ and $0.5 \mathrm{~mm}$, and describe the algorithm as a linear fit from the data shown in the figure, but it is not clear which grain radius, or whether a combination of both, were used. Many authors (e.g. Foster et al., 1997, Kelly et al., 2003, Butt, 2009) have assumed this algorithm relates to a grain radius of $0.3 \mathrm{~mm}$.

To test the effect of variation in grain diameter, we use the Helsinki University of Technology emission model (Pulliainen et al., 1999) driven by a range of snow water equivalents and grain diameters to simulate emission at 19 and $37 \mathrm{GHz}, 53^{\circ}$ from vertical, and apply the Chang algorithm 
to estimate snow mass from this emission, indicating how the algorithm is affected by snow grain diameter. To investigate the effects of variation in snow density, we use a fixed grain diameter and range of snow water equivalents and densities, and apply the Chang algorithm to the emission to retrieve snow water equivalent. For the purposes here, some parameters have a negligible effect (Parde et al., 2007), and are kept constant, eg. soil moisture is assumed $0.1 \mathrm{~m}^{3} \mathrm{~m}^{-3}$, soil temperature $272.15 \mathrm{~K}$, snow temperature $263.5 \mathrm{~K}$, and snow salinity set to zero.

\subsection{The dependence of snow variability on planimetric scale}

A semi-variance analysis is used to examine the characteristic length scale of variability of measured snow properties, to test for evidence that certain spatial scales are more suitable than others for averaging snow properties and estimating snow mass. It is possible that the increased variability of snow properties over large areas mean that the remote sensing relationships with areal snow mass are different, possibly better, than the relationships found at an individual field site. We attempt to identify whether the range of snow properties measured has a strong dependence upon spatial scale by geostatistical analysis of snow properties. The semivariance $\gamma(d)$ for distance $d$ of a set of spatially distributed measurements of $z(\underline{x})$ is given by comparing all pairs of measurements of $z$ separated by $d$, of which there are $n(d)$, using equation (2).

$$
\left.\gamma(d)=\frac{1}{2 n(d)} \sum_{i=1}^{i=n(d)}\left(z \underline{\left(x_{i}\right.}+d\right)-z \underline{\left(x_{i}\right)}\right) \quad \text { Equation (2) }
$$

\section{The NASA Cold Land Processes Experiment (CLPX) experiment produced a large number of} measurements of snow properties, mass, and other variables in Colorado over 2002-2003 (Cline et al., 2002, Cline et al., 2002a, Elder et al., 2009). Figure 1 shows a map of the area of the experiment, and the locations of the main field sites. There were four Intensive Observation Periods (IOPs) during the snow seasons, over the periods February 2002, March 2002, February 2003 and 
March 2003. Anisotropic distance semivariograms were calculated from the measurements of mean snow grain diameter in the top $5 \mathrm{~cm}$ snow layer, snow water equivalent, snow depth, and mean snow density throughout the pack, using the North Park Meso-cell Study Area (MSA) measurements made during IOP3 over 20-23 Feb 2003. Three small intensive sets of measurements within this area were excluded from this analysis, since when analysed separately they showed semivariance consistently around double that of the rest of the measurements, suggesting a different measurement technique with a higher measurement error.

\subsection{Calculation of mean snow properties}

The snow pit measurements made during all four Intensive Observation Periods over the entire area of the CLPX experiment in Colorado were used to calculate the mean snow grain diameter and density within a number of SWE classes. These classes were designed to each encompass snow with a range of SWE with similar properties. Each snow pit measurement set included the minor and major axis diameters of medium size grains, and the mean of these measurements down through the snow layers is used here as representative of the site grain diameter. The depth-integrated mean snow density at each site was used to calculate the mean density within each SWE class.

\subsection{The effects of measured snow properties on snow mass retrieval via the Chang algorithm}

To assess the effects of measured values of density and grain diameter on the accuracy of the Chang algorithm, microwave emission at 19 and $37 \mathrm{GHz}$ at $53^{\circ}$ from the vertical was simulated using the HUT model, driven by the mean snowpit measurements of SWE, density and grain diameter within the SWE classes described in Section 2.3. For each SWE class, we applied the Chang algorithm to the modelled emission, and compared the SWE estimated by the algorithm to the SWE driving the emission model. To distinguish between the effects of grain diameter and density, they were 
153

separately changed within the forward model from the Chang algorithm assumptions to the measured class mean values. This demonstrates, for any given SWE, how accurately the Chang algorithm would estimate snow mass, depending on whether its assumptions of grain diameter and snow density are correct, or whether one or both more closely correspond in reality to the measurements on the CLPX site.

\subsection{The effect of heterogeneity in snow properties on snow mass retrieval via the Chang algorithm}

To test the hypothesis that the spatial heterogeneity in snow properties over a large area improves the accuracy of the Chang algorithm, the microwave emission from a snowpack with the distribution of SWE found within CLPX site was modelled. Having considered the case of a simple, homogeneous snowpack, where the density and grain diameter are a function of SWE in Section 2.4 above, we here consider a more realistic heterogeneous snowpack, with the range of density and grain diameter occurring in the CLPX site within each SWE class. We simulated this by estimating probability density functions (PDFs) of these properties within each class, rather than, as in Section 2.4, simply using the mean of class measurements. In this case, the relationship between modelled and retrieved SWE was calculated for each class by modelling the emission for a range of density/grain diameter combinations, 20 density values between $40 \mathrm{kgm}^{-3}$ and $400 \mathrm{kgm}^{-3}$, and 27 grain diameter between $0.2 \mathrm{~mm}$ and $5.4 \mathrm{~mm}$, and weighting the mean emission according to the PDFs. This allows us to predict for a site with any given SWE, what the algorithm estimate of SWE will be, if the site has a plausible distribution of grain diameter and density. The effect on the overall SWE estimation from a site with the distribution of SWE measured within North Park MSA during IOP3 was also calculated. 
2.6. Comparison of snow mass estimates from satellite data to ground measurements.

179 We empirically tested the accuracy of the Chang algorithm by calculating the remotely-sensed SWE 180 for the site for each of the IOPs, using the SSM/I (Brodzik, 2003) and AMSR-E (Brodzik, 2003a) 181 measurements taken within the ground measurement time span. Armstrong \& Brodzik (2001) show 182 that reducing the brightness temperature difference in this equation by $5 \mathrm{~K}$ provides more accurate 183 results with $\mathrm{SSM} / \mathrm{I}$ data, primarily because the algorithm was designed for $18 \mathrm{GHz}$ and $37 \mathrm{GHz}$ 184 measurements, rather than the $19 \mathrm{GHz}$ and $37 \mathrm{GHz}$ used by SSM/I and AMSR-E, and we apply this 185 correction in applying the algorithm.

3. Results

3.1. The sensitivity of the Chang algorithm to snow grain diameter and density

The Figure 2(a) ordinate shows the SWE used to simulate snowpack emission, the abscissa shows the SWE that would be retrieved from this emission using the Chang algorithm, and the 1:1 line represents a perfect retrieval. The retrieval which assumes a grain diameter of $0.8 \mathrm{~mm}$ follows the perfect retrieval 1:1 line closely for low SWE, which suggests that the algorithm constant proposed in Chang et al. (1987) was chosen to work with a snow grain diameter of $0.8 \mathrm{~mm}$, or a radius of $0.4 \mathrm{~mm}$, mid-way between the two radii $0.3 \mathrm{~mm}$ and $0.5 \mathrm{~mm}$ showed in the figure. Using

197 Chang et al. (1987)'s Figure 1, it is easy to show that if only the $0.3 \mathrm{~mm}$ radius emission curves had 198 been used to calculate the constant, as has been widely assumed, the ratio between SWE and $199\left(\mathrm{~TB}_{18 \mathrm{H}}-\mathrm{TB}_{37 \mathrm{H}}\right)$ would have been around 6, rather than the 4.77 given (after assuming snow density 200 of $300 \mathrm{kgm}^{-3}$ ), yielding SWE estimates $26 \%$ higher than an estimate based on the $0.3 \mathrm{~mm}$ radius 
assumption. The coefficient given seems to derive from the mean of the ratio between SWE and $\left(\mathrm{TB}_{18 \mathrm{H}}-\mathrm{TB}_{37 \mathrm{H}}\right)$ at $40 \mathrm{~cm} \mathrm{SWE}$, averaged across both $0.3 \mathrm{~mm}$ and $0.5 \mathrm{~mm}$ snow grain radii.

204 Figure 2(b) shows the algorithm's sensitivity to variation in density assuming the grain diameter is 205 fixed at $0.8 \mathrm{~mm}$. The effect ranges from underestimation at density of $400 \mathrm{kgm}^{-3}$ to overestimates of 206 a factor of six at a density of $50 \mathrm{kgm}^{-3}$. It can be seen that the algorithm is most accurate where the 207 density and grain diameter exactly match the values used to formulate the algorithm, and that it 208 starts to fail above about 150mm SWE. The suggestion in Chang et al. (1987) that the algorithm not 209 be applied to snow depth greater than 1 meter, equivalent to approximately $300 \mathrm{~mm}$ SWE given a 210 snow density of $300 \mathrm{kgm}^{-3}$, seems to be a judgment based on the degree of acceptable error, possibly 211 around a SWE estimation error of $10 \%$.

213 The relationships between modelled and estimated SWE shown in Figure 2 strongly suggest that the 214 Chang algorithm constant was formulated to fit snow with a grain diameter of $0.8 \mathrm{~mm}$, rather than 215 the $0.6 \mathrm{~m}$ diameter, $0.3 \mathrm{~mm}$ radius often assumed. The impact of this misinterpretation on subsequent 216 work is probably small, as the range of snow grainsize found in work citing it (e.g. Foster et al., 217 1997, Kelly et al., 2003, Butt, 2009) is far larger than this discrepancy.

\subsection{The dependence of snow variability on planimetric scale}

The data density in the IOP measurements allowed semivariograms with reasonable uncertainty to be calculated between lags of $5 \mathrm{~km}$ and $25 \mathrm{~km}$. These showed negligible change in semivariance of mean grain diameter, density and snow water equivalent over this lag range. Mean grain diameter showed a semivariance around $0.27 \mathrm{~mm}^{2}$, regardless of distance lag, suggesting a standard deviation in measurements of $0.7 \mathrm{~mm}$ which is invariant with sample spacing within the $5 \mathrm{~km}-25 \mathrm{~km}$ range.

226 SWE semivariance varies little from $500 \mathrm{~mm}^{2}$, snow depth semivariance is around $70 \mathrm{~cm}^{2}$, and mean 
227 density semivariance $3000 \mathrm{~kg}^{2} \mathrm{~m}^{-6}$. This suggests that heterogeneity is scale-independent over the $2285 \mathrm{~km}-25 \mathrm{~km}$ distance range. We have therefore not considered further the effect of spatial scale 229 within this work, as the sampling density within these data will not provide reliable results outside 230 this range.

232 The only other comparable work in geostatistical analysis of snow properties covers the northern 233 Great Plains region of the USA (Chang et al., 2005), and indicates that ground-measured snow 234 depth has a nugget (minimum) semivariance of about $100 \mathrm{~cm}^{2}$, and reaches a sill (maximum) of 235 approximately $400 \mathrm{~cm}^{2}$ at a lag of $500 \mathrm{~km}$. The $70 \mathrm{~cm}^{2}$ snow depth semivariance in the CLPX 236 measurements indicates that they are more consistent than those taken during the Great Plains 237 fieldwork, possibly reflecting a more accurate measurement system. Assuming this to be the case, 238 the lack of a trend in semivariance across the $5 \mathrm{~km}-25 \mathrm{~km}$ lag range would not be inconsistent with 239 the semivariance behaviour within the Great Plains data, which varied little over the same distance 240 range. The implication that might be deduced from this is that in order to estimate snow variability 241 over a $25 \mathrm{~km}$ scale, sampling a sub-area of $5 \mathrm{~km}$ should prove adequate. This result may well not be 242 globally applicable however, as the measurement sites in this experiment were of necessity close to 243 roads rather than evenly distributed through the area, and the range of snow depth is not globally 244 representative.

\subsection{Calculation of mean snow properties}

248 The class SWE ranges, and means of snow density and grain diameter within the classes for the 249 observations made over Intensive Observation Periods (IOPs) 1, 2, 3 and 4 at the CLPX Colorado 250 site are shown in Table 1, and illustrated in Figure 3. Snow water equivalent measurements were 251 made to the nearest whole mm. 
253 The snow properties for snow mass in the sub-300mm SWE range where we expect the Chang 254 algorithm to be effective show considerable deviation from the values assumed in the algorithm. 255 Whilst measurements using different techniques can give a variety of snow grain size estimates, 256 making the absolute grain size values subject to interpretation, the considerable variability in snow 257 grain diameter in the low SWE range should be reflected by any self-consistent measurement 258 system. In this data, snow diameter only reaches a value consistently close to that assumed by the 259 Chang algorithm above $300 \mathrm{~mm}$ SWE, in a regime where the algorithm is not applied because of 260 nonlinearity in the modelled relationship. Similarly, there is a substantial variation in the range of 261 snow density at low SWE, mostly more than $100 \mathrm{kgm}^{-3}$ below the $300 \mathrm{kgm}^{-3}$ algorithm assumption. 262 The mean snow density over all pits during IOP3 was in fact $145 \mathrm{kgm}^{-3}$, less than half the algorithm 263 assumed value. This dataset has limitations, since the pit locations are of necessity close to roads, 264 and the snow depth is relatively low, however it remains the most appropriate for this work, and 265 similar measurements taken at Reynolds Creek Experimental Watershed over thirty years (Marks el 266 al, 2000) show a similar relationship between density and SWE, with density about $30 \mathrm{kgm}^{-3}$ higher 267 than the CLPX measurements for SWE below 300mm.

269 3.4. The effects of measured snow properties on snow mass retrieval via the Chang algorithm

271 The effect of using the mean snow grain diameter and density measurements from the CLPX site 272 (Table 1, Figure 3) in the emission model is shown in Figure 4. The snow water equivalent used in 273 the forward modelling is shown along the ordinate; the abscissa denotes the snow water equivalent 274 calculated from the simulated microwave emission driven by the measured mean values of mean 275 snow density and grain diameter. A line shows the 1:1 mapping expected if the Chang algorithm exactly calculated the snow water equivalent. The other lines show the mapping between the input 
SWE and that derived from applying the Chang algorithm to the HUT model driven by these different assumptions of snow grain diameter and density :-

- Snow grain diameter of $0.8 \mathrm{~mm}$ and density of $300 \mathrm{kgm}^{-3}$, both as assumed by the Chang algorithm

- Snow grain diameter of $0.8 \mathrm{~mm}$ as assumed by the Chang algorithm, snow density according to the CLPX measurements in Table 1

- Snow grain diameter according to the CLPX measurements in Table 1, snow density $300 \mathrm{kgm}^{-3}$, as assumed by the Chang algorithm

For most of the range of SWE, the algorithm overestimates SWE by a factor of between 2 and 3 .

The relative effects of the deviation from the algorithm values of grain diameter and density can be seen by replacing the algorithm values used within the emission model individually. The dashed

290 line shows that using the algorithm grain diameter of $0.8 \mathrm{~mm}$ in the HUT model, and using only the 291 density from the snowpit measurements gives rise to a small increase in the estimated SWE over the 292 expected retrieval. Using the snowpit grainsize measurements with the $300 \mathrm{kgm}^{-3}$ algorithm density 293 in the emission model gives a far greater estimated SWE difference, indicating that the difference 294 between the grainsize assumed in the algorithm and that measured in the snow pits is the dominant 295 cause of this SWE over-estimation. Below 300mm SWE, the mean departure from exact retrieval 296 caused by the CLPX-measured grain size is just over five times greater than that caused by using 297 the CLPX-measured density. 
299 3.5. The effect of heterogeneity in snow properties on snow mass retrieval via the Chang 300 algorithm

302 The Chang algorithm estimates of SWE from the HUT-simulated emission are shown in Figure 5, 303 for each class for homogeneous snow, and heterogeneous snow where variability in individual pit 304 measurements is incorporated. The mean simulated emission from the 109 North Park MSA pits 305 measured during IOP3 would yield an overall retrieved SWE of $62.4 \mathrm{~mm}$ assuming snow was 306 homogeneous within the SWE classes, and $72.8 \mathrm{~mm}$ for heterogeneous snow. The field measurements of SWE used to drive the emission model had a mean of $23.8 \mathrm{~mm}$.

The heterogeneity does not seem to make a significant difference, though there is an apparent reduction for SWE above $150 \mathrm{~mm}$. This would imply, for example, that a snow pack with a mean

311 SWE of $200 \mathrm{~mm}$ with the range of snow properties seen at this site for such a SWE would have a retrieved SWE of 370, whereas a snowpack with a SWE of 200mm and appropriate uniform mean

313 properties would have a retrieved SWE around 500mm. For most of the SWE regime, this indicates 314 that the variation in properties seen on this scale does not give rise to a substantial improvement in 315 soil moisture retrieval from the Chang algorithm.

3.6. Comparison of snow mass estimates from satellite data to ground measurements.

319 Whilst SSM/I measurements were available for all four IOPs, AMSR-E measurements were only 320 available for IOPs 3 and 4. Snow liquid water content was assessed qualitatively on-site by those 321 taking the physical measurements for a number of pits as either 'dry', 'moist' or 'wet', and the results are tabulated in Table 2. These indicate that during IOP2, the snow was judged to be far 
323 wetter than during the other periods, and we expect the estimation accuracy to be poor in such 324 conditions.

326 The snow mass estimates calculated from the satellite-measured brightness temperatures and the mean of the snow water equivalent snow-pit measurements is plotted for each IOP in Figure 6; the temporal extent of the snow-pit lines indicates the time span of the pit measurement campaign. The SWE estimates based on applying the Chang algorithm to the mean brightness temperatures during each campaign are also given in Figure 6, with the mean of the pit SWE measurements for each 331 IOP.

These figures show an estimated mean snow mass calculated from SSM/I and AMSR-E measurements approximately twice the value measured on the ground, in line with the analysis of Section 3.4 and Figure 4. For IOP3, where AMSR-E measurements are also available, they are somewhat lower than those based on the SSM/I measurements, through it is difficult to draw conclusions from such a small set of observations. The estimation fails as expected for the IOP2 measurements because the liquid water within the snow has substantially reduced penetration of the $19 \mathrm{GHz}$ radiation through the snow pack.

\section{Conclusions}

Based on the physical properties of the snow measured at the CLPX Colorado site, and the HUT microwave emission model, snow mass calculations using the Chang algorithm overestimate snow mass by a factor of two or more, predominantly because of the assumption of fixed grain diameter, which shows substantial variation in the SWE range below about $300 \mathrm{~mm}$ where the algorithm is usable. This overestimation does not appear to be significantly affected by the heterogeneity in snow properties exhibited at the site over a $25 \mathrm{~km}$ distance. 
350 While the CLPX measurements only indicate the range of variation of snow properties at one site,

351 we have no reason to believe that this site is exceptionally heterogeneous, or that the snow found in 352 the rest of the world corresponds more uniformly to the assumptions implicit in the Chang 353 algorithm. The SWE overestimation found by Pardé et al. (2007) in Central Canada suggests a snow 354 pack with similar grainsize characteristics to those found at the CLPX site. While the retrieved 355 effective grain diameter fitted in their retrieval shows a mean diameter around $3 \mathrm{~mm}$, between $2 \mathrm{~mm}$ 356 and $4.5 \mathrm{~mm}$, ground measurements ranged between $1.3 \mathrm{~mm}$ and $3.2 \mathrm{~mm}$. The sensitivity plot 357 Figure 2(a) indicates that the underestimates found by Armstrong \& Brodzik (2000) in data from 358 the former Soviet Union, and Butt (2009) in the UK, could be attributed to a snow grain diameter 359 around $0.6 \mathrm{~mm}$.

361 Estimation of snow mass from its interaction with microwave radiation is strongly affected by other 362 snow characteristics, and consequently any improvement in snow mass retrieval via passive 363 microwave measurement will require grain size information. This could be acquired by a 364 simultaneous retrieval from microwave observations or possibly from visible and infra-red snow 365 surface reflectivity, which has been shown to be strongly dependent on grain diameter (Nolin and 366 Dozier, 2000). Tedesco et al. (2007) developed an approach based on this, and using MODIS 367 AQUA and TERRA near-infrared measurements of the CLPX area we have studied in this work, 368 North Park MSA, estimated the grain diameter of the top snow layer with an accuracy of 369 approximately $0.18 \mathrm{~mm}$. This result should be considered in the context of the gap of a day between 370 satellite data acquisition and ground truth due to cloud conditions, and the difference between the 371 punctual ground measurements and the area-integrated estimates imposed by the 500m wide 372 MODIS pixels. 
374 While this approach will not provide explicit information on the grain diameter throughout the 375 height of the snow pack, it is possible that a physical model of the snow pack, driven by a range of 376 measurements such as reflectivity-derived surface grain diameter estimates from satellite 377 instruments, and numerical weather predictions of temperature and precipitation, could provide the 378 necessary grain size information. Improved characterisation of snow structure could be used to 379 drive a multilayer version of the single-layer HUT model used here (Lemmetyinen et al., 2010). 380 Such a system would serve not only to improve our ability to invert an emission model to derive 381 snow mass from passive microwave emission, but also to indicate where the emission model, and 382 therefore the inversion, will fail. For example, the temperature within the snow pack would indicate 383 where melt and refreeze events are likely, flagging where the presence of ice lenses and liquid water 384 will cause problems for the emission model. The dynamic relationship between the physical model, 385 the emission model and the observations suggests the need for a data assimilation framework to 386 improve snow mass estimation. Data assimilation can be used to provide estimates of the snow 387 properties through physically-based simulations of the snow cover, constrained by independent 388 remote sensing estimates of eg. the grain size. These snow properties are then used to drive a 389 microwave emission model. Comparison between observed and simulated brightness temperatures 390 can be used to update the state of the modelled snowpack, and should enable more accurate 391 retrievals of snow mass. 
395 This work was funded under the National Centre for Earth Observation, Natural Environment 396 Research Council, UK.

References

400 Armstrong, R.L. \& Brodzik, M.J., (2000). Validation of passive microwave snow algorithms, Proc. 401 IGARSS 2000, 24-28 Jul 2000, vol. 4, 1561-1563

Armstrong, R. L. \& Brodzik, M. J. (2001). Recent Northern Hemisphere snow extent: A 404 comparison of data derived from visible and microwave satellite sensors. Geophysical Research 405 Letters, 28, 2676-3673.

406

Brodzik., M.J., Editor. (2003). CLPX-Satellite: SSM/I Brightness Temperature Grids. Boulder, CO: 408 National Snow and Ice Data Center. Digital Media.

410 Brodzik, M.J., Editor. (2003a). CLPX-Satellite: AMSR-E Brightness Temperature Grids. Boulder, 411 CO: National Snow and Ice Data Center. Digital Media.

413 Butt, M.J., (2009). A comparative study of Chang and HUT models for UK snow depth retrieval, 414 International Journal of Remote Sensing, Volume 30, Issue 24, 6361 - 6379

416 Chang, A. T. C., J. L. Foster \& D. K. Hall (1987). Nimbus-7 SMMR derived global snow cover parameters, Ann. Glaciol., 9, 39-44 
419 Chang, A. T. C., Kelly, R. E., Josberger, E. G., Armstrong, R. L., Foster, J. L., \& Mognard, N. M. 420 (2005). Analysis of ground-measured and passive-microwave-derived snow depth variations in 421 midwinter across the northern Great Plains. Journal of Hydrometeorology, 6(1), 20-33.

Clifford, D. (2010). Global estimates of snow water equivalent from passive microwave instruments: history, challenges and future developments. International Journal of Remote Sensing, 31(14):3707-3726

Cline, D., Elder, K., Davis, B.J., Liston, G.E., Imel, D., \& Yueh, S.H. (2003). Overview of the

NASA cold land processes field experiment (CLPX-2002), Proc. SPIE, Vol. 4894, 361;

Cline, D., Armstrong, R., Davis, R., Elder, K. \& Liston, G. (2002), Updated July 2004. CLPX

Digital Media.

Cline, D., Armstrong, R., Davis, R., Elder, K., \& Liston, G. (2002a), Updated July 2004. CLPX-

Ground: ISA Snow Pit Measurements. Edited by M. Parsons and M.J. Brodzik. Boulder, CO:

National Snow and Ice Data Center. Digital Media.

Elder, K., Cline, D., Liston, G.E., \& Armstrong, R. (2009) NASA Cold Land Processes Experiment 
445 Foster, J. L., Chang, A. T. C., \& Hall, D. K. (1997), Comparison of snow mass estimates from a 446 prototype passive microwave algorithm and a snow depth climatology. Remote Sens. Environ. $447 \quad 62: 132-142$.

449 Kelly, R. E., Chang, A. T., Tsang, L. \& Foster, J. L. (2003), A prototype AMSR-E global snow 450 area and snow depth algorithm, IEEE Trans. Geosci. Remote Sens., 41(2), 230-242, doi: $451 \quad 10.1109 /$ TGRS.2003.809118.

453 Lemmetyinen, J.; Pulliainen, J.; Rees, A.; Kontu, A.; Yubao Qiu; Derksen, C. (2010), 454 Multiple-Layer Adaptation of HUT Snow Emission Model: Comparison With Experimental Data, 455 IEEE Trans. Geosci. Remote Sens., 48(7) 2781-2794, doi: 10.1109/TGRS.2010.2041357

Marks, D., Cooley, K.R., Robertson, D.C., \& Winstral, A. (2000), ARS Technical Bulletin NWRC2000-5, August 11, 2000, Snow monitoring at the Reynolds Creek Experimental Watershed, Idaho, USA snow, Remote. Sens. Environ., 74(2), 207-216

464 Pardé, M., Goïta, K., \& Royer, A. (2007). Inversion of a passive microwave snow emission model 465 for water equivalent estimation using airborne and satellite data, Remote Sensing of Environment $466111(2007) 346-356$

468 Pulliainen, J. T., Grandell, J., \& Hallikainen, M. T. (1999). HUT snow emission model and its 469 applicability to snow water equivalent retrieval, IEEE Trans. Geosci. Remote Sens., 37(3), 1378470 1390, doi: 10.1109/36.763302. 
472 Randall, D.A., \& Wood, R.A., 2007, Climate models and their evaluation, in Climate Change 2007:

473 The physical science basis. Contribution of working group 1 to the fourth assessment report of the

474 intergovernmental panel on climate change, edited by Solomon, S. and et al., Cambridge University

475 Press, Cambridge, UK and New York, NY, USA.

476

477 Tedesco, M., \& Kokhanovsky, A. A. (2007). "The semi-analytical snow retrieval algorithm

478 and its application to MODIS data." Remote Sensing of Environment, 111(2-3), 228-241.

479 
Table 1. Classes defined by SWE ranges, and mean snow properties within the ranges over all pits for IOPs $1,2,3,4$

\begin{tabular}{|c|c|c|c|c|c|}
\hline \multirow{2}{*}{ Class } & \multicolumn{2}{|c|}{ SWE range (mm) } & \multirow{2}{*}{$\begin{array}{l}\text { Mean density } \\
\left(\mathrm{kg} / \mathrm{m}^{3}\right)\end{array}$} & \multirow{2}{*}{$\begin{array}{l}\text { Mean grain } \\
\text { diameter }(\mathrm{mm})\end{array}$} & \multirow{2}{*}{$\begin{array}{l}\text { Number of } \\
\text { pits used }\end{array}$} \\
\hline & Lower & Upper & & & \\
\hline 1 & 3 & 7 & 122 & 0.46 & 66 \\
\hline 2 & 8 & 10 & 120 & 0.58 & 33 \\
\hline 3 & 11 & 13 & 138 & 0.59 & 29 \\
\hline 4 & 14 & 17 & 152 & 0.76 & 32 \\
\hline 5 & 18 & 24 & 191 & 1.21 & 32 \\
\hline 6 & 25 & 44 & 225 & 1.21 & 53 \\
\hline 7 & 45 & 68 & 235 & 1.25 & 29 \\
\hline 8 & 69 & 86 & 223 & 1.46 & 5 \\
\hline 9 & 87 & 104 & 244 & 1.35 & 12 \\
\hline 10 & 105 & 163 & 230 & 1.36 & 55 \\
\hline 11 & 164 & 221 & 235 & 1.40 & 28 \\
\hline 12 & 222 & 290 & 253 & 1.00 & 36 \\
\hline 13 & 291 & 433 & 281 & 0.99 & 69 \\
\hline 14 & 434 & 570 & 298 & 0.96 & 65 \\
\hline 15 & 571 & 700 & 318 & 0.93 & 38 \\
\hline 16 & 701 & 825 & 341 & 0.80 & 21 \\
\hline 17 & 826 & 1029 & 354 & 0.72 & 11 \\
\hline 18 & 1030 & 1282 & 336 & 0.73 & 6 \\
\hline
\end{tabular}


Table 2. Snow moisture assessment as a percentage of the number of pits with an estimate.

\begin{tabular}{|c|c|c|c|}
\hline Period & Dry & Moist & Wet \\
\hline IOP1 & $55 \%$ & $35 \%$ & $9 \%$ \\
\hline IOP2 & $40 \%$ & $10 \%$ & $50 \%$ \\
\hline IOP3 & $49 \%$ & $49 \%$ & $3 \%$ \\
\hline IOP4 & $58 \%$ & $42 \%$ & $0 \%$ \\
\hline
\end{tabular}




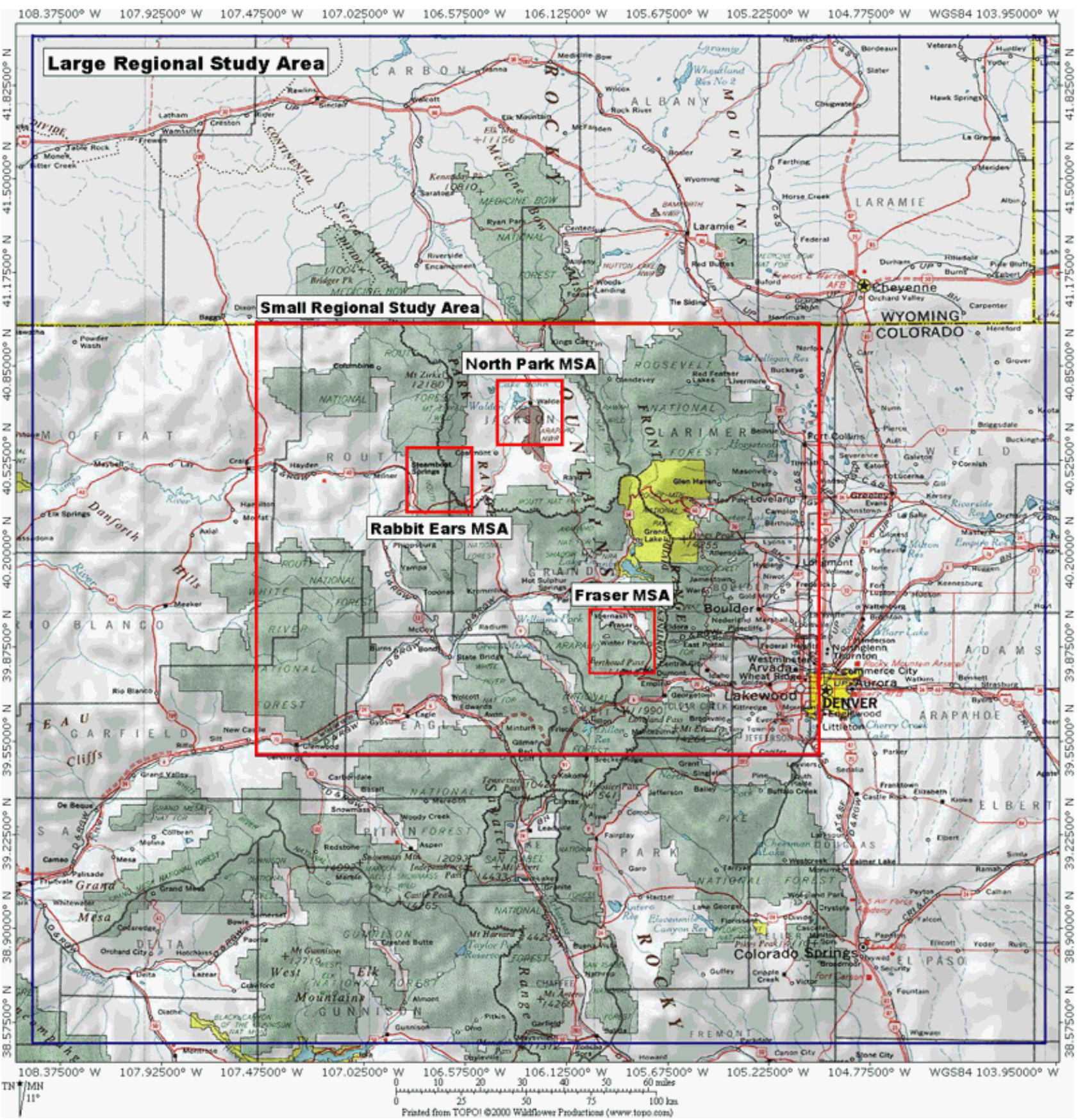

Figure 1. Nested study areas for the Cold Land Processes Field Experiment

(after http://www.nohrsc.nws.gov/ cline/clpx.html)

COLOUR, ONLINE VERSION 


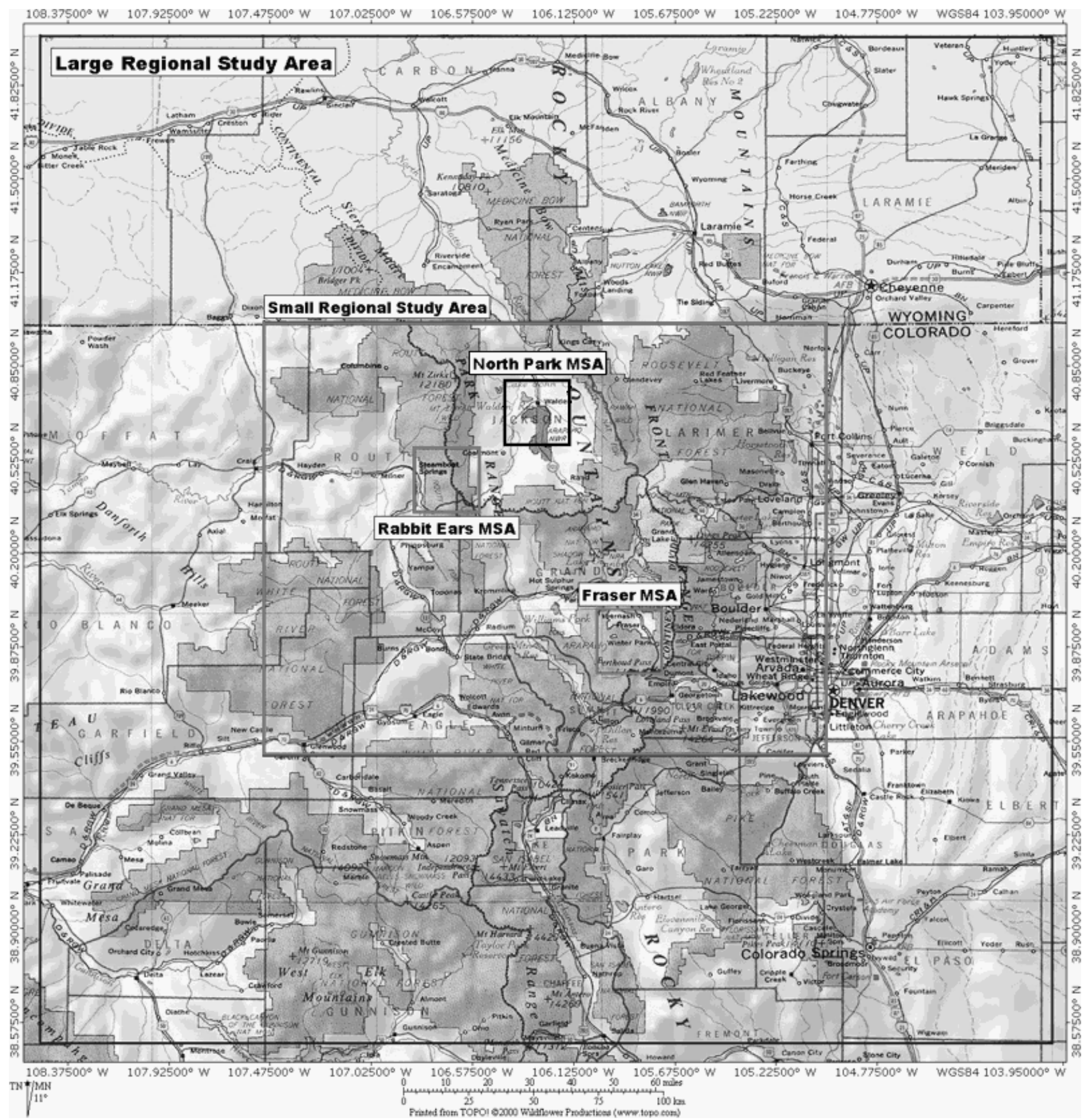

Figure 1. Nested study areas for the Cold Land Processes Field Experiment

(after http://www.nohrsc.nws.gov/ cline/clpx.html)

GREYSCALE, PRINT VERSION 


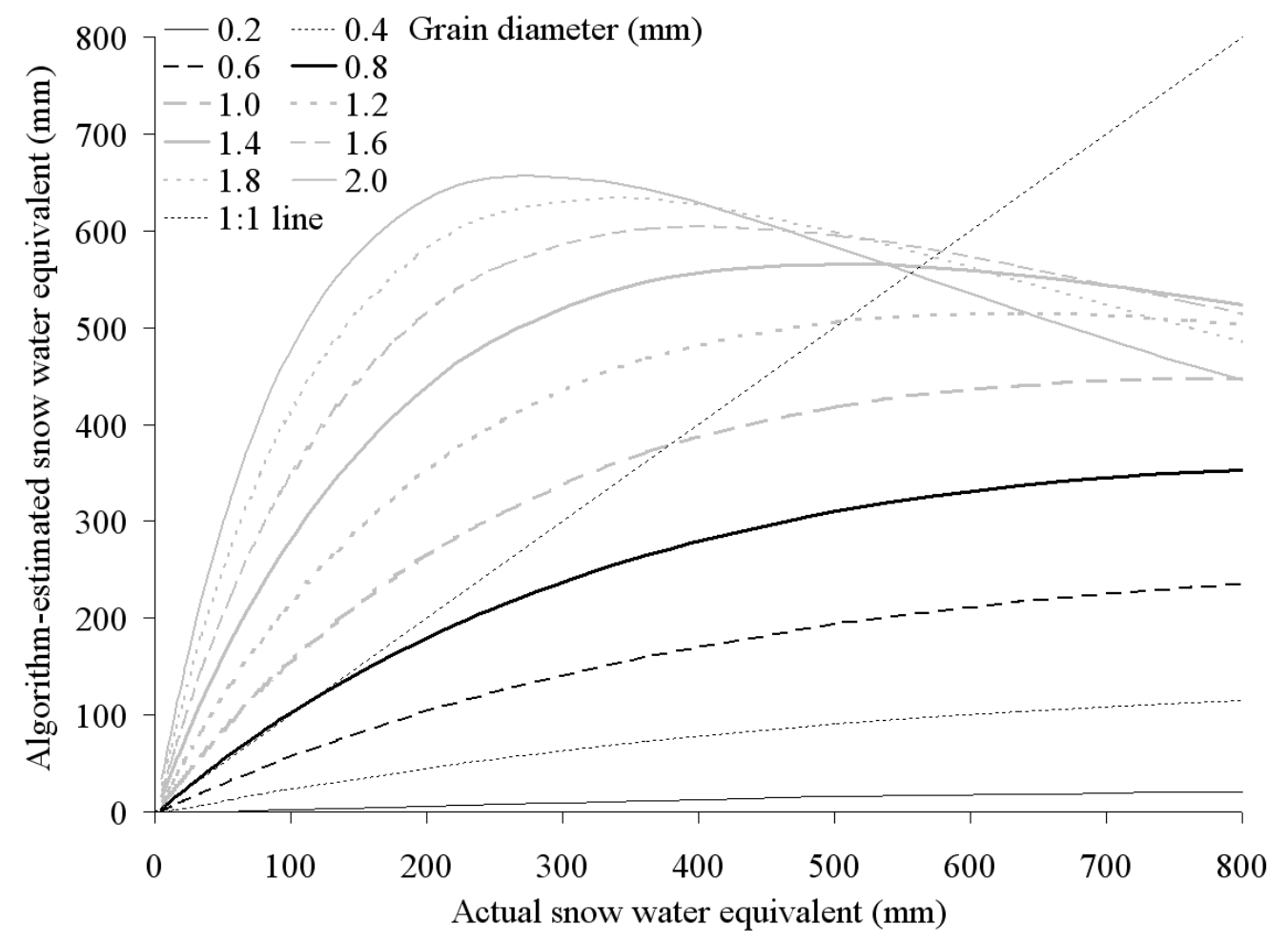

(a) Retrieval error caused by deviation of snow grain diameter from ideal value of $0.8 \mathrm{~mm}$ while snow density is fixed at $300 \mathrm{~kg} \mathrm{~m}^{-3}$.

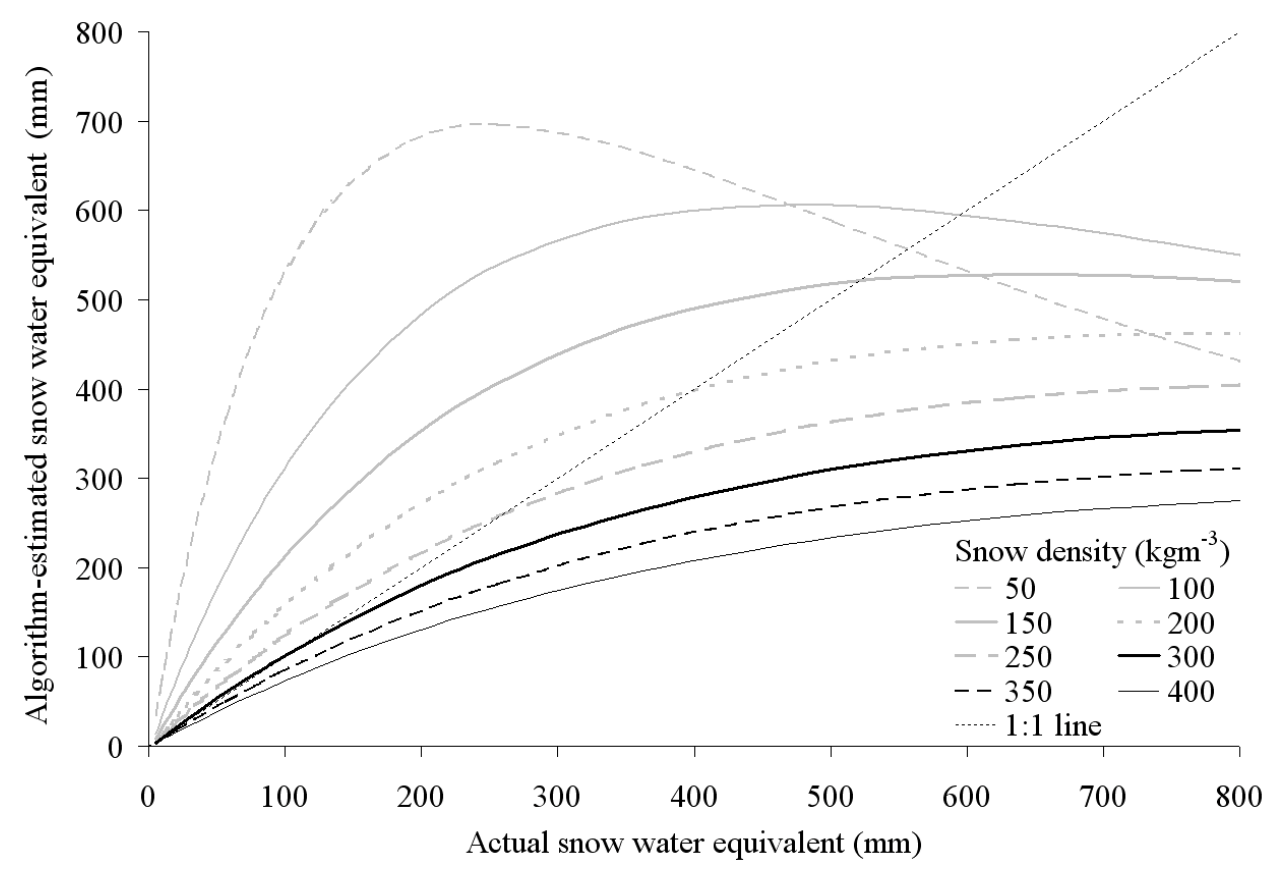

(b) Retrieval error caused by deviation of snow density from ideal value of $300 \mathrm{~kg} \mathrm{~m}^{-3}$ while snow grain diameter is fixed at $0.8 \mathrm{~mm}$.

Figure 2. Chang algorithm retrieval error caused by deviation of snow grain diameter and density from ideal values. 


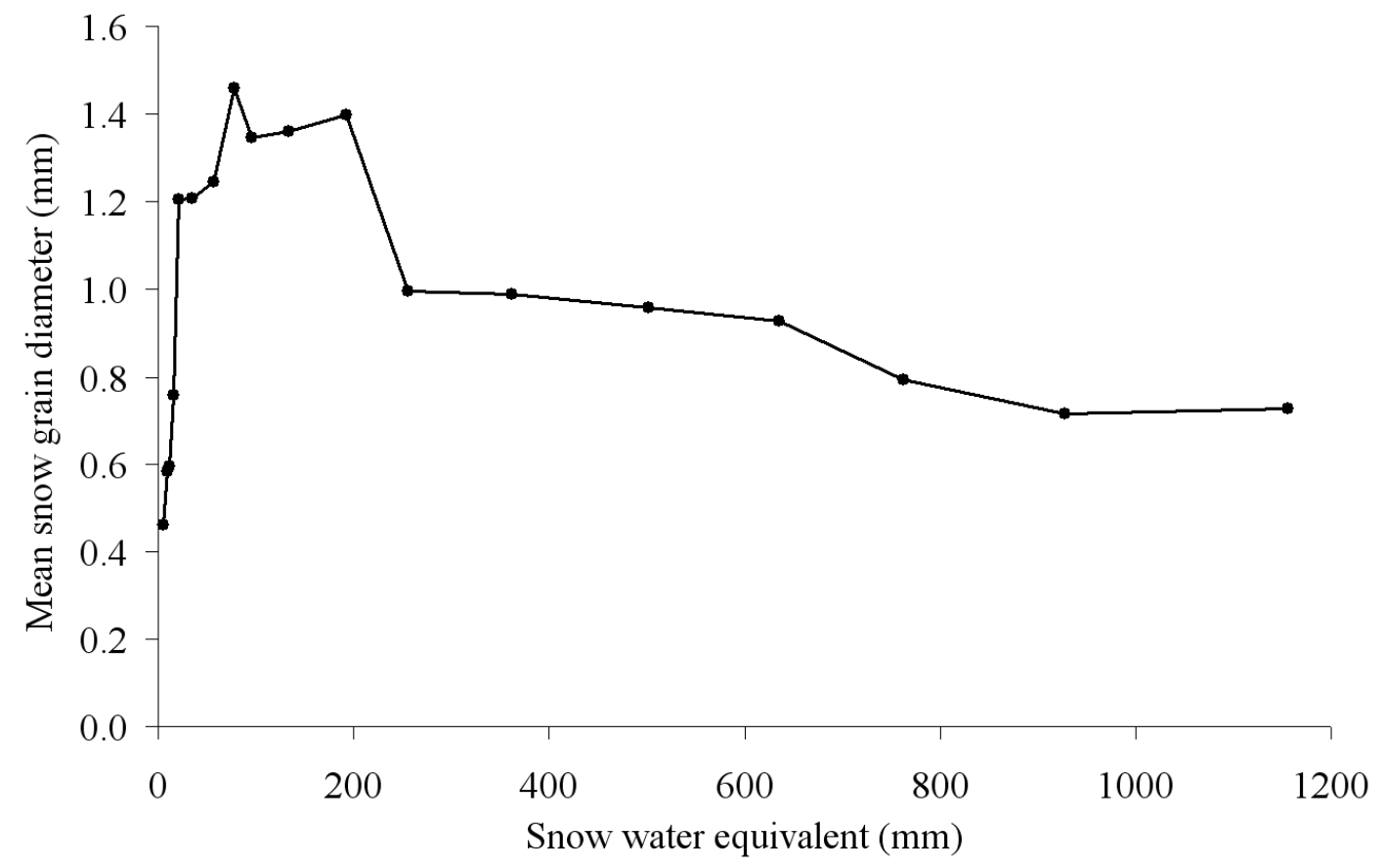

(a) Snow grain diameter

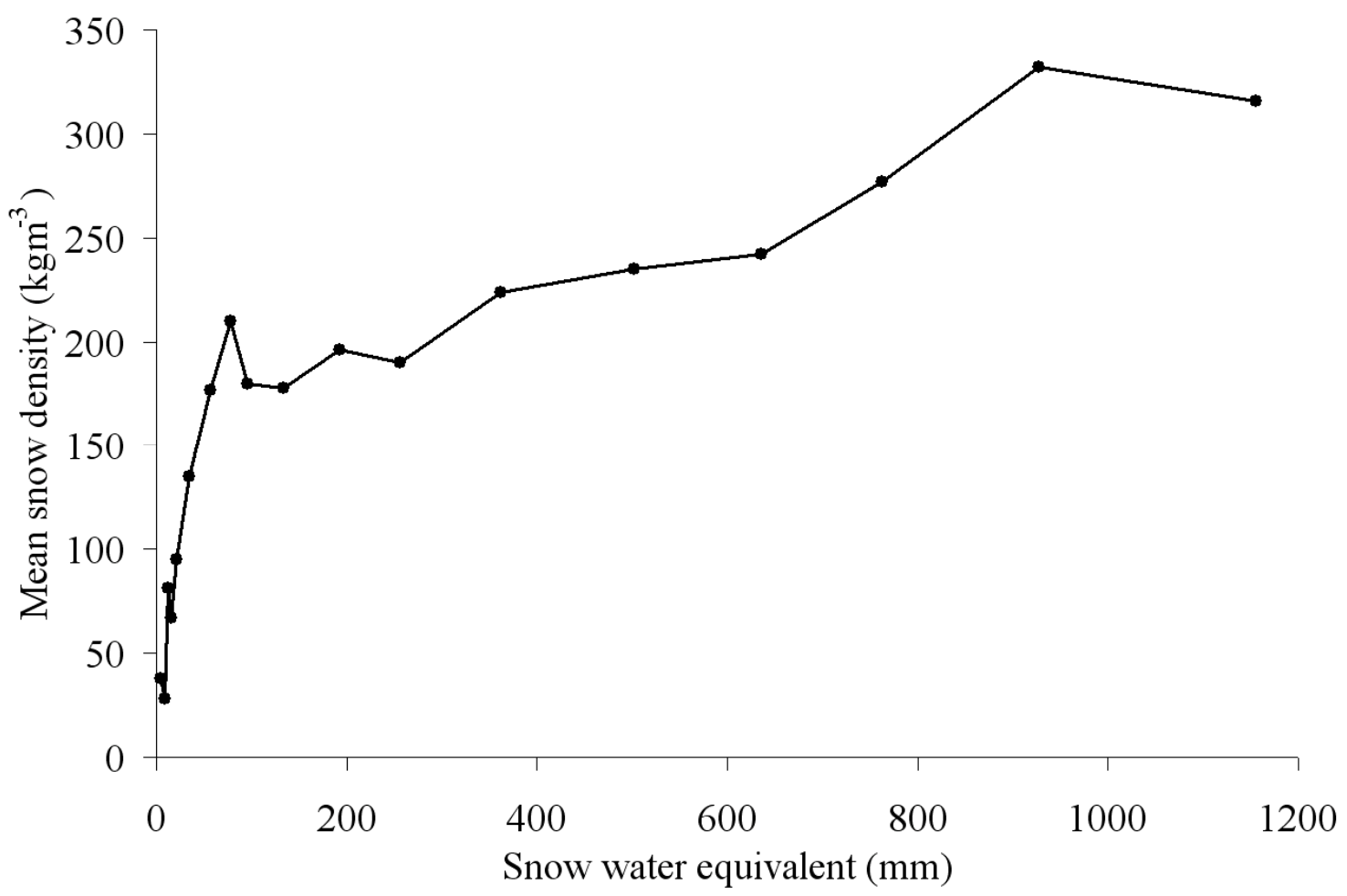

(b) Snow density

Figure 3. Mean snow properties within SWE classes calculated from CLPX measurements. 


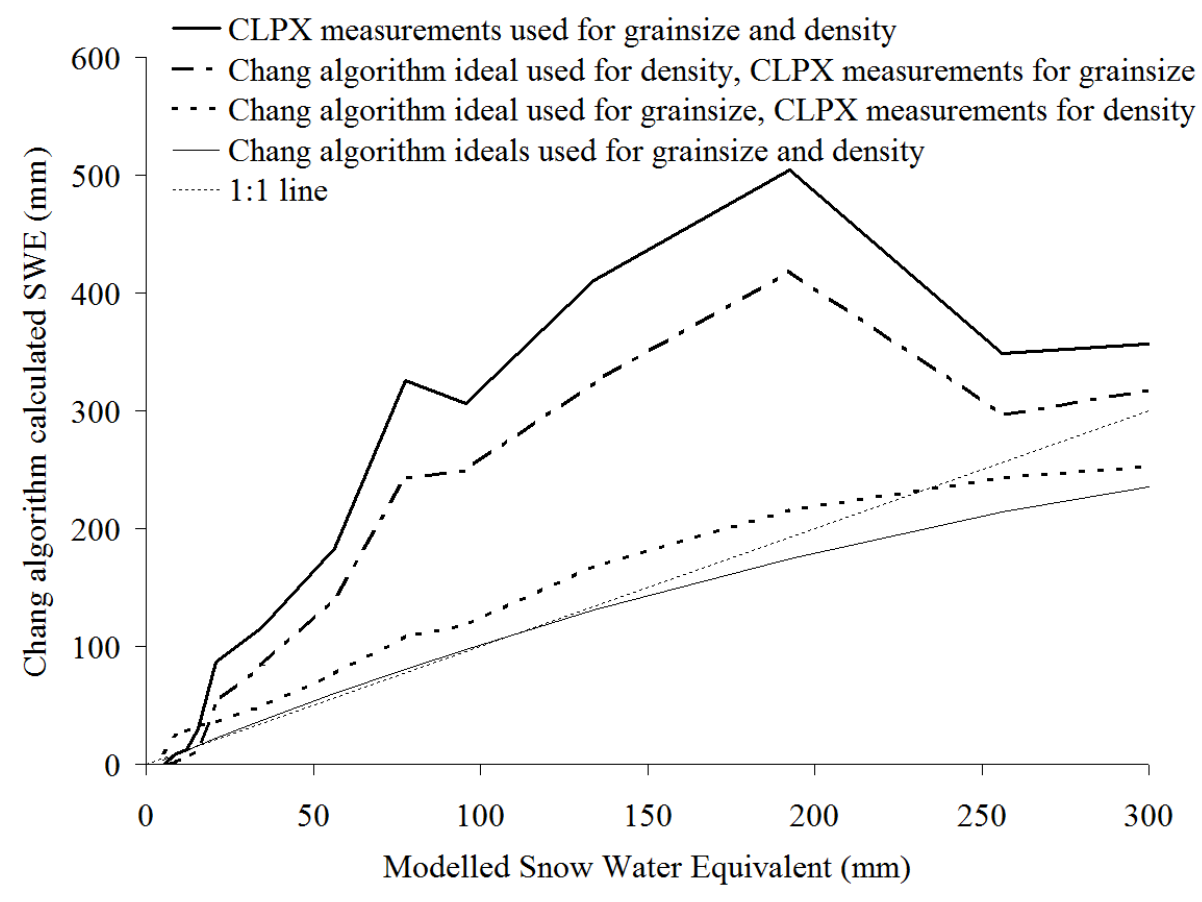

Figure 4. The effect of CLPX snow grain diameters and densities on the accuracy of snow water equivalent retrieval from the Chang algorithm, using the HUT model to calculate microwave emission.

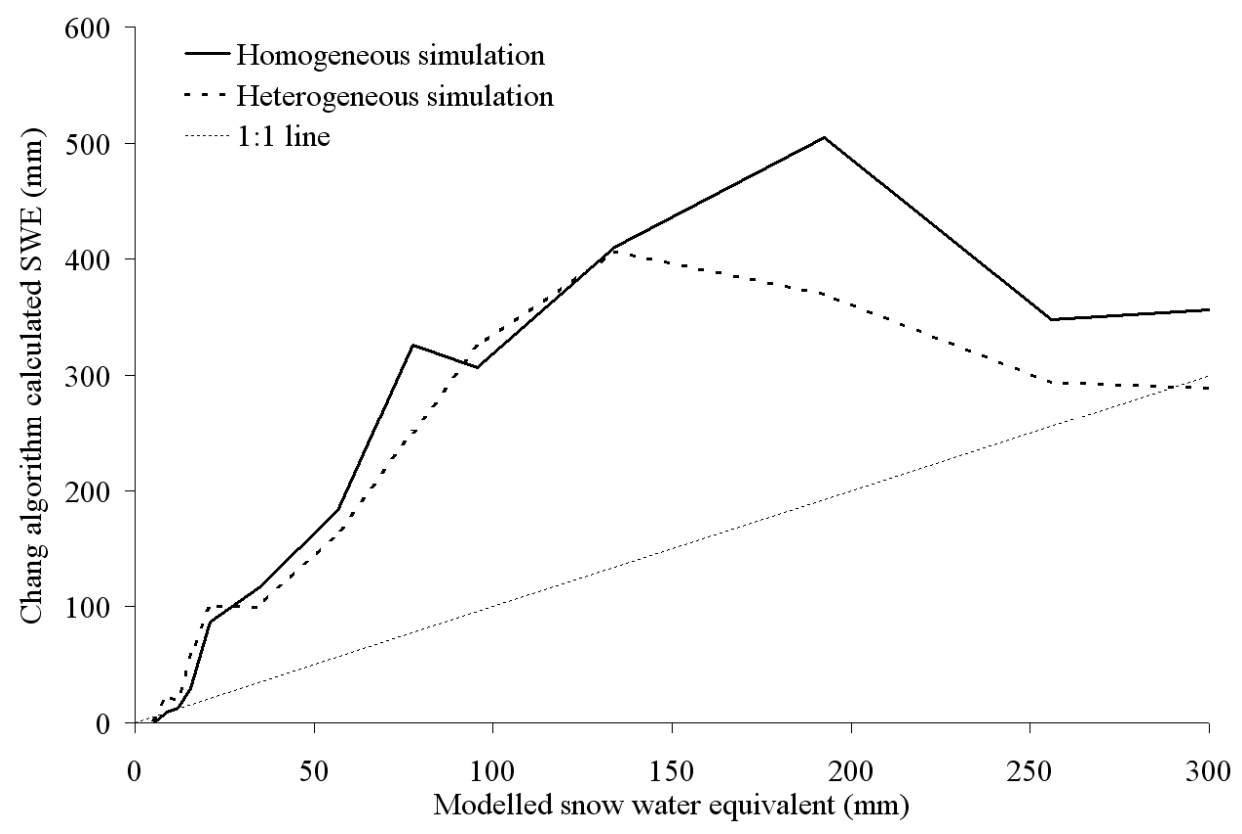

Figure 5. Snow water equivalent retrieved from microwave emission simulated by using CLPX measurements in the HUT model. Mean snow characteristics within each SWE class are used for the homogeneous line, the heterogeneous line uses a distribution of snow characteristics within each class derived from the CLPX measurements to reflect measured snow variability. 


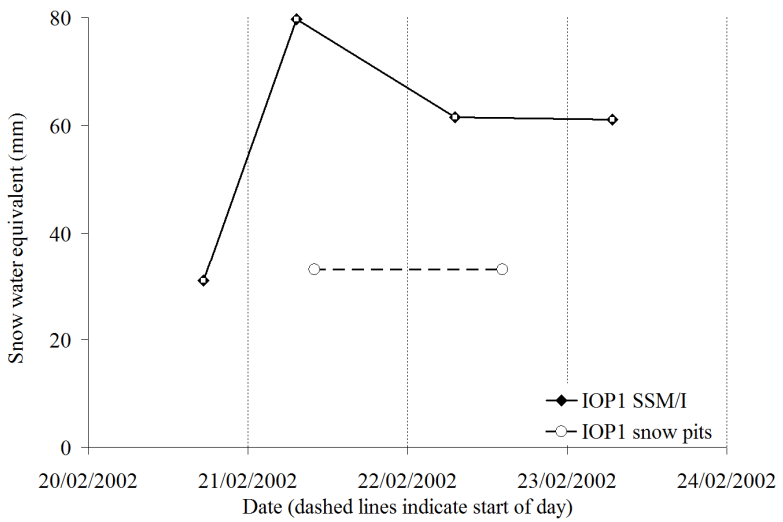

(a) IOP1, 20-24 Feb 2002, mean pit-measured

\section{SWE $33.1 \mathrm{~mm}, \mathrm{SSM} / \mathrm{I} 70.6 \mathrm{~mm}$}

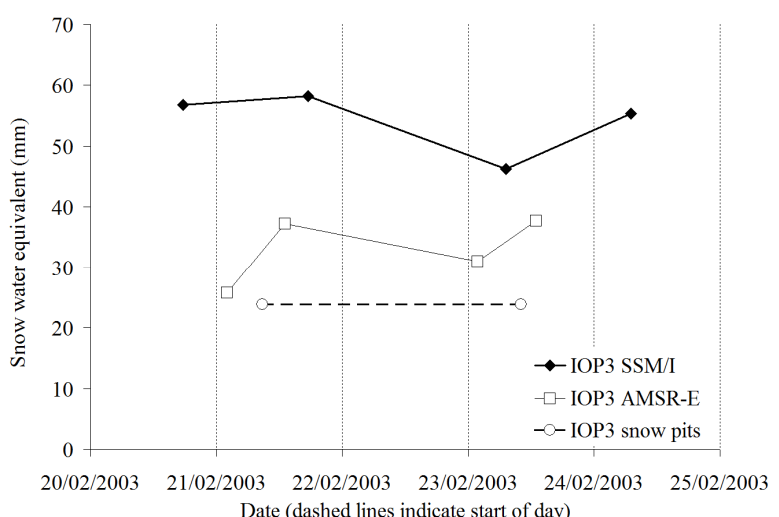

(c) IOP3, 20-23 Feb 2003, mean pit-measured

SWE 23.8mm, SSM/I 52.2mm, AMSR-E

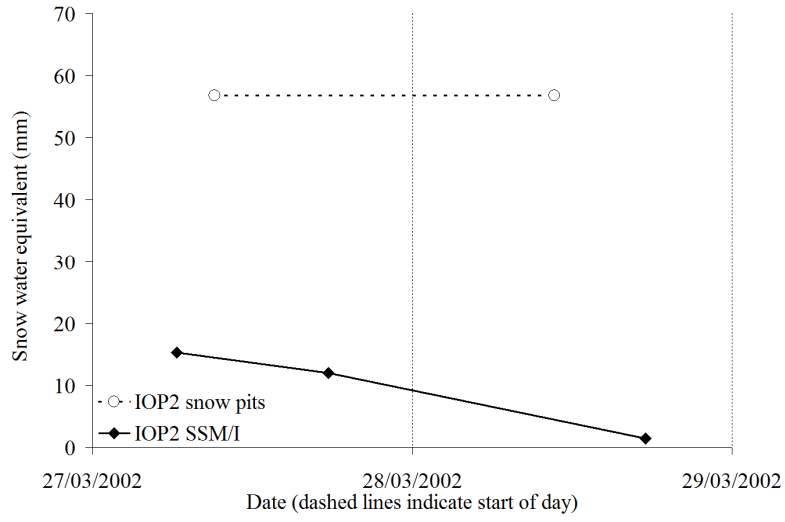

(b) IOP2, 27-28 March 2002, mean pit-measured SWE 56.8mm, SSM/I 9.5mm

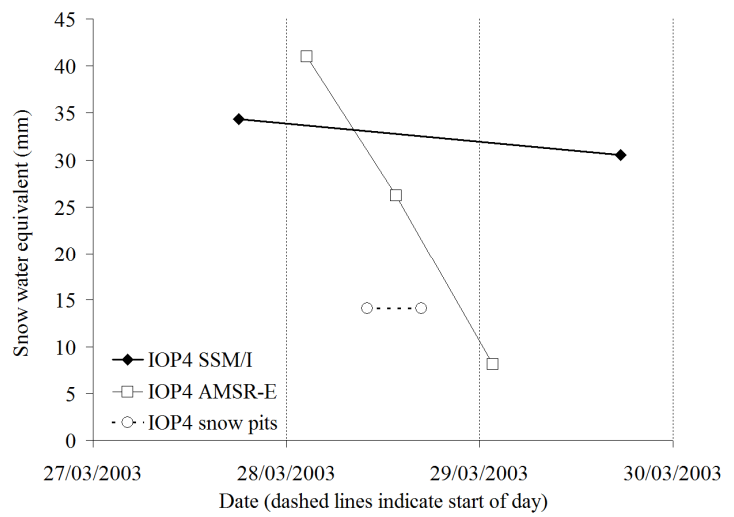

(d) IOP4, $28^{\text {th }}$ March, 2003, mean pit-measured SWE $14.1 \mathrm{~mm}, \mathrm{SSM} / \mathrm{I} 32.4 \mathrm{~mm}$, AMSR-E $25.1 \mathrm{~mm}$

\section{$32.9 \mathrm{~mm}$}

Figure 6. Snow water equivalent in CLPX North Park MSA during the four Intensive

Observation Periods, measured during ground campaigns and estimated from SSM/I and AMSR-E satellite data using the Chang algorithm. 